This is a self-archived version of an original article. This version may differ from the original in pagination and typographic details.

Author(s): Mikkola, Leena

Title: Supportive Communication in the Workplace

Year: 2020

Version: Accepted version (Final draft)

Copyright: @ 2020 Taylor \& Francis Group

Rights: In Copyright

Rights url: http://rightsstatements.org/page//nC/1.0/?language=en

Please cite the original version:

Mikkola, L. (2020). Supportive Communication in the Workplace. In L. Mikkola, \& M. Valo (Eds.), Workplace Communication (pp. 149-162). Routledge. https://doi.org/10.4324/9780429196881-

12 


\section{Supportive Communication in the Workplace}

\section{Leena Mikkola}

Supportive communication is a form of social interaction that produces resources with which to solve situational problems and manage emotional strain. Through the management of uncertainty, supportive communication enhances the perception of personal control over life events and strengthens the perception of acceptance. It is enacted in the seeking of support, in providing support, and in supportive listening as a form of emotional and informational support. In the workplace, supportive communication is crucially important: It promotes productive work and employees' well-being as well as job satisfaction and engagement in the organization. This chapter presents the foundations of supportive communication, reviews existing knowledge of social support and supportive messages, and applies this knowledge to workplace communication. The chapter also discusses the development of supportive communication in workplace.

\section{Introduction}

Knowledge work consists of thinking and social interaction. Even though such work is mostly very interesting, exciting, and rewarding, it can sometimes cause stress. Large amounts of information, intense concentration, significant problem-solving, manifold responsibilities, fragmented workdays, and strict deadlines may result in substantial cognitive load and emotional strain. Employees sometimes need to draw on social resources to cope with such problems. According to the constitutive perspective on communication (Manning 2014), workrelated well-being is constructed in workplace interaction. It is a resource for maintaining healthy work conditions and a primary source of mental well-being at work. Supportive communication and supportive relationships in the workplace create resources through uncertainty management, which enhances employees' sense of control over work-related stress and strengthens their sense of acceptance.

Supportive communication has many important outcomes in the workplace. There is evidence that social support in the workplace strengthens one's job motivation, job commitment, and job satisfaction. Social support also affects the quality of the outcomes of work processes. Supportive relationships form a solid basis for working, and in knowledge work, mutual support plays a major role in achieving high-quality results, such as creative problem-solving and decision-making. Supportive relationships may also reinforce learning and the construction of a professional identity. This chapter describes supportive communication in the workplace as a process of seeking, providing, and receiving informational and emotional support. The aim of the chapter is to analyze existing knowledge about the forms of supportive communication, including listening, and apply it to the workplace context. The chapter also discusses issues related to the creation of a healthy, supportive workplace. 
Social Support as Uncertainty Management and Sensemaking

Supportive communication - that is, communicating social support - is a form of social interaction that produces cognitive, emotional, and relational resources with which to solve situational problems and manage emotional strain. It is verbal and nonverbal communication "produced with the intention of providing assistance to others perceived as needing that aid" (MacGeorge, Feng, \& Burleson 2011, 317). Supportive interaction consists of processes of seeking, providing, and receiving support. In the workplace, supportive communication can be observed in the communication behavior of workplace members as they engage in social interaction: How coworkers express their need for support, how support is provided, how coworkers respond to the provision of support, and whether someone is listening supportively. Supportive communication works through the process of uncertainty management. Uncertainty emerges when there is a lack of information, that is, a lack of sufficient cues with which to interpret the situation and to anticipate what will happen in the future (see Kramer 2003). Uncertainty may also arise from ambiguous, complex, unpredictable, and probabilistic situations (Brashers 2001). Social support is a form of interpersonal communication that helps people manage uncertainty by enhancing the perception of personal control over life events (Albrecht \& Goldsmith 2003). Through social support, one's perception of acceptance is strengthened as well (Mikkola 2009). Even though working life events, such as strict project timelines that can create an excessive workload, are not controllable as such, viewing a given situation and its future consequences from the perspective of prospects can provide some relief. Supportive communication may result, for instance, in highlighting different strategies to follow. Social support helps people manage uncertainty in a way that helps them maintain hope and somewhat optimistic expectations (Brashers 2001). These resources of uncertainty management are constructed in social interaction, in which new meanings are created for the situation or problem at hand.

In the workplace, the origins of uncertainty are manifold. Uncertainty may emerge from various sources: (1) certain work tasks or stressful situations, such as strict deadlines; (2) the employees themselves, as when an employee experiences insecurity regarding their job competence and professional identity; (3) issues related to coworkers, such as the quality of their performance or attitudes toward shared work tasks; or (4) issues of reciprocity in relationships, such as the presence or absence of mutual trust (see Albrecht \& Adelman 1987). For example, young physicians often locate the origin of their work-related stress - which gives rise to their need for social support - in the substantial responsibilities and requirements of clinical work and 
their limited possibilities to control their workload. Simultaneously, the origin of their uncertainty is internal, because they frequently fear that they lack sufficient knowledge and competence to perform their work successfully. (Mikkola, Suutala, \& Parviainen 2018.) In a stressful situation, individuals make cognitive evaluations of the connection between themselves and the situation; these evaluations are called appraisals (Lazarus 1991). Appraisals are personal meanings. A primary appraisal is a personal definition imputed to the situation or event. A secondary appraisal follows the primary one: it is the meaning given to the alternative courses of action in a given situation. When processing the situation, reappraisals, i.e., new meanings for the situation, take place. (ibid.) Supportive communication facilitates the emergence of reappraisals, which mitigates the stress (Goldsmith \& Burleson 1998).

For instance, in a situation where a project team member is offered a new job, their primary appraisal may be either it is the possibility to proceed in their career, or less attractively, it means a fully booked diary of work. When the latter course is taken, the secondary appraisal may create the meanings of extreme workload but also of positive work rearrangements that lead to very different conclusions. When the appraisals are straining, supportive communication makes it possible to create new meanings that decrease uncertainty. In workplace communication, sensemaking is the process by which these meanings are constructed. Uncertainty is managed through sensemaking (Kramer 2003).

\section{Emotional and Informational Support}

Social support is usually categorized into informational, emotional, and instrumental support. Emotional and informational support emerge intrinsically in social interaction, but instrumental support - that is, receiving concrete help and resources, including time - is concrete and material in nature. However, instrumental support is also provided in interaction, and communication therefore plays a central role in the way instrumental support is provided and received. Emotional and informational support emerge solely from social interaction.

Emotional Support

Emotional support enables employees to vent their emotions and to gain psychological distance from the emotional reactions that emerge in a stressful situation. It is in social interaction that an employee aims to help the other party lessen their emotional distress (Burleson 2003). The content of emotion-centered messages focuses on the emotional reactions caused by a stressful situation. The messages aim to identify, appraise, evaluate, and describe the emotions (Goldsmith \& Dun 1997). 
A central function of emotion-centered messages is legitimizing feelings, that is, validating emotional reactions instead of criticizing or belittling them. Legitimizing feelings is one dimension of person centeredness (Burleson 1987), a specific feature of supportive messages that is crucially important in explaining the effectiveness of social support, especially emotional support. Person centeredness is the feature of communication that "reflects an awareness of and adaptation to subjective, affective, and relational aspects of communication context" (ibid., 305). Highly person-centered messages are those in which the support provider explicitly expresses an understanding of the uniqueness of the stressful situation and the emotional burden it causes. The support provider is also sensitive to the relational dimension of communication, which is enacted, for example, by supportive listening (see Bodie \& Jones 2012). Messages with weak person centeredness, on the other hand, are those that deny the other's perspective (MacGeorge, Feng, \& Burleson 2011).

There is strong evidence that person centeredness is a crucial consideration when evaluating the perceived effects of social support (High \& Dillard 2012) and the perceived effectiveness of supportive messages (e.g., Burleson et al. 2005). Person centeredness also explains the long- term effects of supportive communication. Long-term effects also require the receiver's ability and motivation to process the messages (Bodie \& Burleson 2008; the dual-processing model of supportive communication). The support receiver's motivation to process supportive messages is influenced by personal factors, such as one's perceptions of relationship characteristics (e.g., trustworthiness and reciprocity) and one's locus of control, which is the perceived degree of control over life events. The situational factors that influence motivation include the quality of the stressful situation, the content of supportive messages, and the timing of supportive communication. The support receiver's ability to process supportive messages consists of personal factors, such as interpersonal skills, and situational factors, such as possible obstacles to the interaction (ibid.).

If the support receiver is motivated and able to process supportive messages, effects are generated, but they are mainly short-term. However, it is the person centeredness that produces perceived long-term effects. (ibid.) Interaction and the messages created and interpreted are more important factors for long-term effectiveness of social support than individual or situational factors. Interaction triggers individual processes, and supportive communication, such as discussions with a coworker, facilitates reappraisals (Burleson \& Goldsmith 1998). This is how social support has outcomes that enhance well-being. Even though cognitive processing takes place on the individual basis, the meaning creation is social. 


\section{Informational Support}

Informational support involves providing information that is relevant for the person in need of support. When providing informational support, it is essential that the knowledge offered helps to control uncertainty, because large amounts of information may also increase uncertainty and stress. All knowledge is not necessarily supportive, and in certain situations uncertainty may be more desirable than certainty (Brashers 2001).

Informational support is enacted in problem-centered and solution-centered messages. The content of problem-centered messages focuses on analyzing and evaluating the problematic situation and the factors causing the stress (Goldsmith \& Dun 1997). Problem-centered messages do not necessarily provide new information, but they arrange the existing information and offer new interpretations of it. In solution-centered messages, the content focuses on identifying and evaluating alternative courses of action (ibid.). In contrast to problem-centered messages, solution-centered messages are directed at pondering on potential ways of acting rather than analyzing the problem. Solution-centered messages do not necessarily aim directly at finding solutions, but they support the aim of identifying news ways of thinking about courses of action for the person in need.

In the workplace, informational support is crucial for high-quality outcomes. Both problemcentered and solution-centered messages have their own importance. Problem-solving is the core task of knowledge work, and not all problem-solving is based on social support; much of it is integrated into typical work practices. At their best, supportive message skills are developed and informally learned in daily work processes. However, it is also important to be sensitive in communication situations in order to recognize when a colleague may be in need of support in their problem-solving process. Being aware of different functions of interpersonal communication and different situational goals is of vital importance.

Giving advice is one form of instrumental support. Advice consists of recommendations regarding how to think, how to feel, and what to do (MacGeorge, Feng, \& Thompson 2008). Good advice is evaluated on the basis of its feasibility and efficacy (Feng \& MacGeorge 2010). Similarity, closeness, and interpersonal affinity improve the reception of advice (Bonaccio \& Dalal 2010), which emphasizes the importance of a mutual relationship between the support seeker and support provider. However, as Feng and MacGeorge (2010; advice response theory) suggest, even though the credibility and expertise of the advice provider influence how the advice is received, the effectiveness of advice is more likely to depend on the content and style of the message than on the characteristics of the advice provider. Also in informational support, interpersonal communication is the central facilitator. 
Providing advice can be challenging. The recipient's face - that is, their desire to maintain a selfperception of being liked and competent and their desire to be regarded as an autonomous actor (Brown \& Levinson 1987) - may be threatened. For example, being blunt or thoughtlessly frank when giving advice or participating in problem-solving can threaten the face of the recipient. Such threats can be mitigated with facework that makes use of strategies such as being indirect, avoiding disagreements, and using hedges, i.e. words that lighten and soothe the intended content (see Feng \& Burleson 2008). It may be easier for some people to receive advice if it is preceded by expressions of emotional support (Feng 2009), and the quality of advice is connected to the support seeker's confidence about handling the problem (Feng \& MacGeorge 2010).

\section{Dynamics of Supportive Interaction}

Social support is enacted in social interaction through seeking, providing, and receiving support (MacGeorge, Feng, \& Burleson 2011). Moreover, listening is a major part of supportive communication (Bodie \& Jones 2012). When a support seeker recognizes that they need assistance, they make a decision regarding whom to appeal to for help (Dirks \& Metts 2010). Even though providing support may be based solely on the provider's inherent sensitivity to the needs of the other, the support seeker's decision often activates the supportive interactions. This decision is often followed by support-seeking expressions and subsequently by a supportive or avoidant response from the support provider, and finally by the support seeker's response (Cunningham \& Barbee 1995). In the workplace, these kinds of supportive episodes which may be brief or continue further - take place among peer coworkers and leaders, in both formal settings and everyday workplace discussions.

\section{Seeking Support}

Social support is essential in coping with work-related stress. Coworker support may be sought when there is a heavy workload accompanied by a lack of resources. Coworker support is also sought in order to identify solutions to professional questions and for assistance in problemsolving (Gilstrap \& Bernier 2017). The support seeker usually turns to a coworker whom they believe is particularly suited to the given issue or problem (Dirks \& Metts 2010). For instance, an employee may seek advice from one colleague but turn to another to ventilate emotions. Evaluating the potential source of support as competent and willing promotes support seeking (MacGeorge, Feng, \& Burleson 2011), and also positive experiences in earlier support-related encounters enhance the seeking (Brock \& Lawrence 2010). Accordingly, supportive 
relationships may develop in the workplace. However, support may also be sought - depending on the problem at hand - from the person who just happens to be present at the time (Dirks \& Metts 2010).

To express their need for support, people use verbal and nonverbal support-seeking strategies, which may be direct or indirect (Barbee, Rowatt, \& Cunningham 1998). Direct verbal strategies are easily recognized as requests for help. However, the indirect verbal strategies of alluding and hinting - for instance, complaining about one's busyness and workload - are not as easy to recognize. Direct nonverbal strategies, such as crying, usually activate a response from the support provider. However, indirect nonverbal strategies, such as sighing and sulking, may not be easily interpreted as forms of support seeking (see Barbee, Rowatt, \& Cunningham 1998).

In addition to their ambiguity, indirect strategies may not result in the expected outcomes, because they may increase the support provider's uncertainty (Barbee, Derlega, Sherburne, \& Grimshaw 1998). However, using indirect strategies helps to diminish face threats (Goldsmith 1994) and to protect self-esteem (Williams \& Michelson 2008). In knowledge work, where employees are expected to be highly qualified and self-oriented professionals, it may be uncomfortable and embarrassing to ask support in a direct manner. By contrast, the work community may acknowledge that it is acceptable or even necessary to ask for help in order to deal with certain issues or tasks. For instance, it may be common in a certain workplace to share difficulties or emotions regarding client encounters. At the same time, difficulties associated with certain problem-solving tasks may remain concealed because it is assumed that everyone can or should resolve these kinds of problems on their own.

\section{Responding to Support Seeking}

Responding to requests for support takes many forms. Because meanings are created in social interactions, which are situational and contextual and in which participants and their mutual relationship influence the meaning-making, there is no expression that would be perceived as supportive in all situations. The same expression can even be interpreted in entirely opposite ways, and it would be challenging to list helpful and unhelpful behaviors (see Goldsmith 2004). It is always the support receiver who interprets these expressions. For example, advice giving may be interpreted as supportive in some situations but as presumptuous or inappropriate in others. Much depends on the relationship between the support provider and support receiver. If the support receiver interprets that the intention of the other is to help, the receiver probably interprets also the expressions as supportive. The intention underlying supportive messages must be perceived as supportive as well (ibid.). 
However, categorizing potentially supportive responses may shed light on the dynamics of supportive communication. Cunningham and Barbee (1995) suggest that responses to requests for support may take the form of either approaching or avoidance behaviors and that such responses may be either problem-oriented or emotion-oriented. They identify four types of responses: (1) solving; (2) solace; (3) dismissing; (4) and escaping. Solving is a problemoriented approaching response that is enacted, for instance, by asking about the issue, offering a new viewpoint, and suggesting solutions. The focus is on the current problem. Solace is an emotion-oriented approaching response, such as comforting, encouraging, and showing empathy. In contrast to approaching responses, dismissing and escaping are avoidance responses. For example, downplaying the issue and expressing an inappropriate kind of sympathy by using worn-out phrases like "don't worry, it'll pass," without actually focusing on the support seeker, are problem-oriented avoidance responses. Escaping is an emotionoriented avoidance response, and it includes actions like expressing irritation and urging the support seeker to control their emotions (Cunningham \& Barbee 1995).

Responding to support seeking depends partly on motivation. The support provider's willingness to help increases when the cause of the problem is clearly identifiable and external, which means that the support seeker is not solely responsible for the problem (Dunkel-Schetter \& Skokan 1990). Because knowledge-work tasks are often quite abstract, it may be difficult to identify the actual origin of the problem, and it may be also difficult to evaluate how much the support seeker can mitigate the problem on their own. For example, meeting the project deadlines may be due to several different causes. However, it is always possible that the employee personally is responsible for the problem, in which case the support provider will lack the motivation to help.

Problems that are controllable and that can be attributed solely to the support seeker do not necessarily inhibit the provision of support. However, such situations seem to produce more problem-oriented than emotion-oriented messages (MacGeorge 2001). Moreover, the support seeker's own efforts to resolve the problematic situation have an influence on the support provided. When the support seeker demonstrates an effort to deal with the problem, the support provider's motivation to help usually increases. On the contrary, if a colleague repeatedly needs support in the same type of situation, this usually decrease the willingness to help (ibid.). Thus, whether the responses consist of approaching or avoidance behaviors, and whether they are problem-oriented or emotion-oriented, depends on the support provider's motivation. Underlying the motivation are the support provider's interpretations of the support seeker's actions. 


\section{Supportive Listening}

Supportive listening is a dyadic process in which the support seeker and support provider influence each other through disclosing and listening (Jones 2011). Listening is an important part of the dynamics of supportive communication when seeking support and in responding it. Supportive listening is characterized by certain behaviors. Focusing attention on the support seeker, expressing involvement, demonstrating understanding, being verbally responsive, and being kind are the attributes that characterize supportive listeners (Bodie, Vickery, \& Gearhart 2013). A listener is perceived as effective and supportive when the listener's focus is on the speaker's concerns and when the listener is attentive, expresses understanding, and is appropriately responsive by reacting to meanings, not details (Keaton, Bodie, \& Keteyian 2015). Moreover, both verbal person centeredness and nonverbal immediacy are perceived as supportive (Bodie \& Jones 2012). The attributes of supportive listening resemble the characteristics of good listening in personal relationships (Bodie, Vickery, \& Gearhart 2013). However, being supportive does not require a specific relationship, but good listening skills can always reinforce the support provided to a coworker.

In knowledge work, creating, evaluation, and applying information are central tasks. They almost always include analytical listening. One has to be able to differentiate between analytical and supportive listening. Identifying the communication functions in a given situation is important, so that the goals of communication partners could be connected. Supportive listening answers to support seeking, bur analytical and critical listening may even inhibit the support seeker from expressing need of support.

\section{Outcomes of Social Support in the Workplace}

Supportive communication has many important outcomes in working life. The importance of social support in knowledge work is obvious: It results both in better performance in and commitment to the workplace. Social support promotes high-quality performance by increasing emotional affirmation and strengthening the capacity for collective problem-solving (Park, Wilson, \& Lee 2004). It influences the desire to stay and engage in the workplace; both support from leaders and support from peers are antecedents of commitment to the organization (Lambert, Minor, Wells, \& Hogan 2016). Technology-mediated coworker support is also connected to organizational identification (Fay \& Kline 2012). Social support is important in preventing willingness to leave, and it plays a role in decreasing turnover intentions (Feeley et al. 2010). Accordingly, supportive communication in the workplace is beneficial for work 
organizations, because it enhances the commitment of highly skilled professionals to the workplace.

Social support is of course also beneficial for employees' and their well-being. Social support has strong connections with job satisfaction, for example, by mitigating role stress (Singh, Amish \& Singhi 2015). When experiencing role-related stress, social support from an employee's own professional group helps the employee manage both contradictory role expectations and the stress such expectations may generate (Apker, Propp, \& Zabava Ford 2009). Social support received in the workplace may also promote learning and the construction of professional identity. For example, young physicians perceived that social support strengthened their professional competence (Mikkola, Suutala, \& Parviainen 2018). Work-family tension also creates a kind of role stress. Support from leaders enhances well- being by moderating the relationship between well-being and work-family conflict (Lizano et al. 2014), and coworker support reinforces well-being by preventing family-related stress from spilling over into the workplace (Krouse \& Afifi 2007).

The relationship between social support and burnout is well known: Social support prevents burnout (Snyder 2009). For example, in teachers' work, social support mitigates the emotional exhaustion that can result from heavy emotional demands as well as the negative effects of such demands on feelings of personal accomplishment and job satisfaction (Kinman, Wray, \& Strange 2011). Both emotional and informational support play an important role in preventing burnout (Babin, Palazzolo, \& Rivera 2012)

Social support received in the workplace eases work-related stress more effectively than the support received from private life relationships (Sand \& Miyazaki 2000). For example, even though teachers report receiving more support from their friends and family, support received from the leader is evaluated as more important and effective in managing stress (Zhang \& Zhu 2007). The effectiveness of coworker support, from both peers and leaders, may result from a shared understanding of the origins and occurrences of work-related stressors (Ray \& Miller 1991). Understanding work processes and the difficulties they entail makes it possible to focus on essential issues.

In professional work, there is also an obligation to maintain confidentiality, which discourages employees from disclosing their concerns outside the workplace. In the workplace, the employee who needs support and the employee providing it share an understanding of the situation or issue that causes distress. They have a shared understanding of their job, which supports the creation of pertinent supportive messages (Mikkola, Suutala, \& Parviainen 2018). The quality of coworker relationships is naturally a crucial factor in seeking, providing, and 
processing supportive communication (Sias 2009). One special coworker or work friend may have a profound impact on well-being through their affective evaluation of the job (Cranmer et al. 2017).

\section{Practical Implications}

Supportive communication is functional interaction in which meanings related to issues that cause uncertainty and strain are reciprocally created. In supportive communication, the intentions of each party are interpreted and supportive meanings are constructed. Supportive communication is situated and contextual, and a workplace's communication culture is the setting in which supportive communication takes place.

Regardless of whether mutual social support is valued, it influences the seeking and providing of support in the workplace. In the 1960s, Gibb (1961) identified the characteristics of supportive and defensive interpersonal communication. Supportive communication is descriptive and problem centered and involves empathic and egalitarian responses, whereas a defensive communication climate is judgmental and controlling. Because social support enhances both performance and coworkers' well-being, it is worthwhile cultivating a supportive workplace.

A good starting point for creating a supportive workplace is to initiate a discussion of the potential stressors. What produces strain in a particular workplace and in a particular job or task? How can these stressors be recognized? Where are the turning points in work processes that might benefit from supportive problem-solving? Establishing a shared understanding of the potential needs for support helps employees identify the situational factors underlying the strain, which can also decrease misleading attributions of the problem at hand.

It is also important to reflect on existing communication practices. Do they promote supportive interactions? In the workplace, social support is presumably sought in informal situations. However, some problems require more time and space to be addressed. Creating opportunities to speak out regarding one's concerns may facilitate the seeking of support. It is equally important, however, to notice when communication fails to promote well-being. So-called corumination, that is, engaging in excessive discussion of work and workplace problems (Haggard et al. 2011), may easily turn into defensive communication. Being aware of this phenomenon and agreeing that it is appropriate to explicitly identify co-rumination as it arises, may help dismantle this inappropriate practice. Moreover, the habit of "rush talk" - reiterating that one's workdays are overloaded and busy - may reinforce the kind of workplace culture 
that promotes stress. Additionally, it may hinder the provision of support by concealing more substantive needs for support.

Whether a workplace is characterized by long-term relationships or constantly changing project teams, it is acceptable to ask for support. It is also acceptable to discuss the different strategies for seeking and providing support. The role of leaders is important, and social support is expected from leaders in problematic situations. However, the leader cannot take full responsibility for employees' stress, coping, identity building, or problem-solving. Creating a supportive workplace is actualized in social interaction, and the responsibility is shared.

What to Consider in the Workplace

- A shared understanding of stressful and challenging tasks and issues in the workplace helps employees notice the need for support in the workplace.

- It is important to identify discourses that reinforce stress. Employees can cultivate more positive ways to talk about the work.

- Every employee can recognize their own ways of seeking support. If their support-seeking approaches are ineffective or do not produce the desired outcomes, new strategies can be created.

- All workers can evaluate their own skills in supportive communication and reflect on the characteristics of supportive messages. Person centeredness and facework are essential to providing support.

- Talking about supportive communication in the workplace reminds employees of its importance.

\section{References}

Albrecht, T. L. \& Adelman, M. B. 1987. Communicating social support: A theoretical perspective. In T. L. Albrecht \& M. B. Adelman (Eds.) Communicating social support. Newbury Park, CA: Sage, 18-39.

Albrecht, T. L. \& Goldsmith, D. J. 2003. Social support, social networks and health. In T. L. Thompson, A. M. Dorsey, K. I. Miller \& R. Parrott (Eds.) Handbook of health communication. Mahwah, NJ: Lawrence Erlbaum, 263-284.

Apker, J., Propp, K. M. \& Zabava Ford, W. S. 2009. Investigating the effect of nurse-team communication on nurse turnover: Relationships among communication processes, identification, and intent to leave. Health Communication 24, 106-114.

Babin, E. A., Palazzolo, K. E. \& Rivera, K. D. 2012. Communication skills, social support, and burnout among advocates in a domestic violence agency. Journal of Applied Communication 40(2), 147-166.

Barbee, A. P., Derlega, V. J., Sherburne, S. P. \& Grimshaw, A. 1998. Helpful and unhelpful forms of social support for HIV-positive individuals. In V. J. Derlega \& A. P. Barbee (Eds) HIV and social interaction. Thousand Oaks, CA: Sage, 83-105.

Barbee, A. P., Rowatt, T. L. \& Cunningham, M. R. 1998. When a friend is in need: Feelings about seeking, giving and receiving social support. In P. A. Andersen \& L. K. Guerrero 
(Eds.) Handbook of communication and emotion: Research, theory, applications, and contexts. San Diego, CA: Academic Press, 281-301.

Bodie, G. D. \& Burleson, B. R. 2008. Explaining variations in the effects of supportive messages: A dual-process framework. In C. Beck (Ed.) Communication yearbook 32. New York: Routledge, 354-398.

Bodie, G. D. \& Jones, S. M. 2012. The nature of supportive listening II: The role of verbal person centeredness and nonverbal immediacy. Western Journal of Communication 76(3), 250-269.

Bodie, G., Vickery, A. J. \& Gearhart, C. C. 2013. The nature of supportive listening, I: Exploring the relation between supportive listeners and supportive people. International Journal of Listening 27(1), 39-49.

Bonaccio, S. \& Dalal, R. S. 2010. Advice taking and decision-making: An integrative literature review, and implications for the organizational sciences. Organizational Behavior and Human Decision Processes 101(2), 127-151. doi.org/10.1016/j.obhdp.2006.07.001.

Brashers, D. E. 2001. Communication and uncertainty management. Journal of Communication 15(3), 477-497.

Brock, R. L. \& Lawrence, E. 2010. Too much of a good thing: Underprovision versus overprovision of partner support. Journal of Family Psychology 23(2), 181-192. doi:10.1037/a0015402.

Brown, P. \& Levinson, S. C. 1987. Politeness: Some universals in language usage. Cambridge: Cambridge University Press.

Burleson, B. R. 1987. Cognitive complexity. In J. C. McCroskey \& J. A. Daly (Eds) Personality and interpersonal communication. Newbury Park, CA: Sage, 305-349.

Burleson, B. R. 2003. Emotional support skills. In J. O. Greene \& B. R. Burleson (Eds.) Handbook of communication and social interaction skills. Mahwah, NJ: Lawrence Erlbaum, 551-594.

Burleson, B. R. \& Goldsmith, D. J. 1998. How the comforting process works: Alleviating emotional distress through conversationally induced reappraisals. In P. A. Andersen \& L. K. Guerrero (Eds.) Handbook of communication and emotion: Research, theory, applications, and contexts. San Diego, CA: Academic Press, 245-280.

Burleson, B. R., Samter, W., Jones, S. M., Kunkel, A. W., Holmstrom, A. J., Mortenson, S. T. \& MacGeorge, E. L. 2005. Which comforting messages really work best? A different perspective on Lemieux and Tighe's "receiver perspective". Communication Research Reports 22, 87-100.

Cranmer, G. A., Goldman, Z. W. \& Booth-Butterfield, M. 2017. The mediated relationship between received support and job satisfaction: An initial application of socialization resources theory. Western Journal of Communication 81(1), 64-86.

Cunningham, M. R. \& Barbee, A. P. 1995. An experimental approach to social support communications: Interactive coping in close relationships. In B. R. Burleson (Ed.) Communication yearbook 18. Thousand Oaks, CA: Sage, 318-413. 
Dirks, S. E. \& Metts, S. 2010. An investigation of the support process: Decision, enactment, and outcome. Communication Studies 61(4), 391-411.

Dunkel-Schetter, C. \& Skokan, L. A. 1990. Determinants of social support provision in personal relationships. Journal of Social and Personal Relationships 7, 437-450.

Fay, S. J. \& Kline, S. L. 2012. The influence of informal communication on organizational identification and commitment in the context of high-intensity telecommuting. Southern Communication Journal 77(1), 61-76.

Feeley, T. H., Moon, D., Kozey, R. S. \& Lowe, A. S. 2010. An erosion model of employee turnover based on network centrality. Journal of Applied Communication Research 38(2), 167-188. doi.org/10.1080/00909881003639544.

Feng, B. 2009. Testing an integrated model of advice-giving in supportive interactions. Human Communication Research 35, 115-129.

Feng, B. \& Burleson, B. B. 2008. The effects of argument explicitness on responses to advice in supportive interactions. Communication Research 35, 849-874.

Feng, B. \& MacGeorge E. L. 2010. The influences of message and source factors on advice outcomes. Communication Research 37, 537-598.

Gibb, J. 1961. Defensive communication. Journal of Communication 11, 141-148.

Gilstrap, C. M. \& Bernier, D. 2017. Dealing with the demands: Strategies healthcare communication professionals use to cope with workplace stress. Qualitative Research Reports in Communication 18(1), 73-81.

Goldsmith, D. J. 2004. Communicating social support. Cambridge: Cambridge University Press.

Goldsmith, D. J. \& Dun, S. A. 1997. Sex differences and similarities in the communication of social support. Journal of Social and Personal Relationships 14, 317-338. https://doi.org/10.1177/0265407597143003

Haggard, D., Robert, C., \& Rose, A. 2011. Co-rumination in the workplace: Adjustment trade-offs for men and women who engage in excessive discussions of workplace problems. Journal of Business and Psychology 26, 27-40.

High, A. C. \& Dillard, J. P. 2012. A review and meta-analysis of person-centered messages and social support outcomes. Communications Studies 63(1), 98-118.

Jones, S. M. 2011. Supportive listening. International Journal of Listening 25, 85-103. doi:10.1080/10904018.2011.536475.

Keaton, S. A., Bodie, G. D., \& Keteyian, R. V. 2015. Relational listening goals influence how people report talking about problems. Communication Quarterly 63(4), 480-494.

Kinman, G., Wray, S., \& Strange, C. 2011. Emotional labour, burnout and job satisfaction in UK teachers: The role of workplace social support. Educational Psychology 31(7), 843-856.

Kramer, M. W. 2003. Managing uncertainty in organizational communication. London: Routledge. 
Krouse, S. S. \& Afifi, T. D. 2007. Family-to-work spillover stress: Coping communicatively in the workplace. Journal of Family Communication 7, 85-122.

Lambert, E. G., Minor, K. I., Wells, J. B., \& Hogan, N. L. 2016. Social support's relationship to correctional staff job stress, job involvement, job satisfaction, and organizational commitment. Social Science Journal 53, 22-32.

Lazarus, R. S. 1991. Emotion and adaption. New York: Oxford University Press.

Lizano, E. L., Hsiao, H., Mor Barak, M. E., \& Casper, L. 2014. Support in the workplace: Buffering the deleterious effects of work-family conflict on child welfare workers' wellbeing and job burnout. Journal of Social Service Research 40(2), 178-188.

MacGeorge, E. L. 2001. Support providers' interaction goals: The influence of attributions and emotions. Communication Monographs 68, 72-97.

MacGeorge, E., Feng, B. \& Burleson, B. 2011. Supportive communication. In M. L. Knapp \& J. A. Daly (Eds.) The Sage handbook of interpersonal communication. Los Angeles, CA: Sage, 317-354.

MacGeorge, E. L., Feng, B. \& Thompson, E. R. 2008. "Good” and "bad" advice: How to advise more effectively. In Motley, M. T. (Ed.) Studies in applied interpersonal communication. Thousand Oaks, CA: Sage, 145-164.

Manning, J. 2014. A constitutive approach to interpersonal communication studies. Communication Studies 65(4), 432-440. doi:10.1080/10510974.2014.927294.

Mikkola, L. 2009. The perception of acceptance as a function of social support. In Kinney, T.A. \& Pörhölä, M. (Eds.) Anti and pro-social communication: Theories, methods and applications. New York: Peter Lang, 107-116.

Mikkola, L., Suutala, E. \& Parviainen, H. 2018. Social support in the workplace for physicians in specialization training. Medical Education Online, 23(1), 1435114. doi:10.1080/10872981.2018.1435114.

Park, K., Wilson. M. G., \& Lee, M. S. 2004. Effects of social support at work on depression and organizational productivity. American Journal of Health Behavior 28(5), 444-455.

Ray, E. B. \& Miller, K. I. 1991.The influence of communication structure and social support on job stress and burnout. Management Communication Quarterly 4(4), 506-527.

Sand, G. \& Miyazaki, A. D. 2000. The impact of social support on salesperson burnout and burnout components. Psychology \& Marketing 17, 13-26.

Sias, P. M. 2009. Organizing relationships: Traditional and emerging perspectives on workplace relationships. Thousand Oaks, CA: Sage.

Singh, A., P. ,Amish . \& Singhi, N. 2014. Organizational role stress and social support as predictors of job satisfaction among managerial personnel. Journal of Social Service Research 40(2), 178-188.

Snyder, J. 2009.The role of coworker and supervisor social support in alleviating the experience of burnout for caregivers in the human-services industry. Southern Communication Journal 74, 373-389. 
Williams, S. L. \& Michelson, K. D. 2008. A paradox of support seeking and rejection among the stigmatized. Personal Relationships 15(4), 493-509.

Zhang, Q. \& Zhu, W. 2007. Teacher stress, burnout, and social support in Chinese secondary education. Human Communication 10, 487-496. 